\title{
El Ceremonial del funeral del presidente de la Republica y el ceremonial de las asistencias del presidente de la República a las festividades o actos públicos de cualquier índole en México: 1836 y 1842.
}

The Ceremonial of the funeral of the President of the Republic and the ceremonial of the assistances of the President of the Republic to the festivities or public acts of any nature in Mexico: 1836 and 1842

\author{
Dr. José Gómez Huerta Suárez ${ }^{1}$ \\ Centro de Investigación de la Mujer de Colima \\ ppghuerta@gmail.com \\ Recepción: 11/10/18 Revisión: 08/11/18 Aceptación: 08/11/18 Publicación: 28/12/18
}

\section{Resumen}

El ceremonial en el siglo XIX en México, era una herramienta que contribuía a establecer y consolidar lo social, resguardaba privilegios de la clase alta y legitimaba a un sector político. El ceremonial luego entonces es utilizado en ese siglo como un mensaje a través de formalidades y honores. Existen, desde luego, innumerables factores comprendidos en el concepto del ceremonial, como que es una forma de comunicación que se ocupa del protocolo, precedencias estructuradas de relaciones formales. Por lo tanto, revisaremos dos documentos de ceremonial en México en la primera mitad del siglo XIX, uno sobre el culto funerario de un presidente de México y otro relativo a los actos públicos o privados donde concurre el presidente de México.

Palabras clave: actos oficiales, precedencia, ceremonia, funeral.

\section{Abstract}

\footnotetext{
${ }^{1}$ Doctor en Derecho por la UNED (España), Máster en Protocolo por la UNED.
} 
The ceremonial in the nineteenth century in Mexico, was a tool that helped to establish and consolidate the social, protected privileges of the upper class and legitimized a political sector. The ceremonial then is then used in that century as a message through formalities and honors. There are, of course, innumerable factors included in the concept of ceremonial, as being a form of communication that deals with protocol, structured precedences of formal relationships. Therefore, we will review two ceremonial documents in Mexico in the first half of the 19th century, one on the funerary cult of a Mexican president and the other on public or private acts attended by the president of Mexico.

Keywords: official acts, precedence, ceremonial, funeral.

\section{Sumario}

1. Objeto de estudio y estado de la cuestión

2. El Contexto

3. Dos actos Ceremoniales del siglo XIX en México.

4. Conclusiones

5. Bibliografía

\section{OBJETO DE ESTUDIO Y ESTADO DE LA CUESTIÓN}

Cuando el ser humano entendió la muerte como un paso sin retorno, aunque algunos pretendan que le espera otra vida, la duda de que ésta sea posible les lleva a profundas preocupaciones. Al mismo tiempo, cuando el hombre comprendió la inevitabilidad de ese destino, y pudo diferenciarlo del sueño y de la vida, encontró también, la medida de su tiempo.

Si hay un tiempo universal y cíclico, y hay un tiempo humano, supuso que este tiempo podría ser también repetitivo; esta deducción, por demás absurda en nuestra época, le llevo al culto funerario.

El culto funerario, corresponden a una etapa tardía del paleolítico superior donde se encuentran inhumaciones que se llevan a cabo siguiendo ritos complicados, como en Gravettien donde se enterraron hombres con omoplatos de mamut y grandes huesoso como recubrimiento de las sepulturas.

Con el transcurso de los siglos, la comunicación entre los seres, paulatinamente van conformando explicaciones que resuelven las dudas y empiezan a modificar el culto funerario. Por otro lado, las religiones de los seres humanos son fundamentales para estos cultos, si una mujer o un hombre nace en Pakistán, será seguramente musulmán, pero si naciera en Zimbabue, sería animista, o si naciese en algún país latinoamericano, sería católico, todos con sus cultos funerarios distintos pero a la vez con similitudes. Para Carl G. Jung, los hombres del mundo occidental obviamente, están profundamente influidos del 
cristianismo medieval; dice que: "Todo lo que pensamos es fruto de la Edad Media cristiana. Nuestra ciencia misma y, en una palabra, todo lo que se agita en nuestros cerebros está formad, necesariamente, por esa era histórica que vive en nosotros" "Pero no por ello es menos cierto que llevamos en nosotros igualmente la marca de lo que ...precedió" al cristianismo. La existencia primitiva ha arraigado sus tradiciones dentro del cristianismo, "pues la iglesia católica se ha alzado sobre la base de un sincretismo pagano" y añade con espíritu histórico que: “... no hay nada que no tenga su historia; tampoco el cristianismo, aunque pretenda ser una revelación única caída del cielo, deja de tener su devenir propio, siendo sus comienzos, por otra parte de una claridad perfecta. No sólo ciertas prácticas de la misa, ciertos detalles de las prendas sacerdotales están tomadas del pasado pagano, sino que las ideas fundamentales del cristianismo tienen sus antecedentes históricos" ${ }^{2}$.

El rito, del latín ritus: ceremonia o reglas establecidas por la costumbre para actos de culto religioso o profano. El rito, corresponde a la relación entre el creyente y el objeto del mito. (Mythos: del griego, que en su origen significo: palabra, y que luego derivó en discurso, narración, fabula y leyenda. El mito es el elemento abstracto de una necesidad intelectual, resume el pensamiento en una forma concreta, en imágenes que pueden explicar en una forma sencilla una idea existencial, o una preocupación sobre el mundo que nos rodea.)Cuando las catástrofes naturales individuales o grupales se producen, los ritos son de utilidad para restablecer la armonía con los mitos.

Los fenómenos naturales como sequias o inundaciones, las epidemias o el hambre; la muerte y la enfermedad, representan transgresiones a los mitos, por lo que es menester reconciliar al hombre o al grupo con sus creencias. Es común que, cuando un individuo o un grupo humano sufren algún problema, suelen atribuirlo a faltas o transgresiones a las figuras de su mitología. La reconciliación que les permita regresar a un estado natural y armónico, corresponde a los rituales preestablecidos; cuando estos rituales no resuelven el problema, se atribuye a una falta en el rito, o a la poca fe del solicitante. Pero, el rito es el elemento reconciliador entre el hecho que provocó el rompimiento o, mejor dicho, el mito transgredido por los hombres. El rito es un procedimiento que tiene variables de acuerdo con la falta cometida, el rezo, la ofrenda y el sacrificio, son los sistemas que ayudan en este proceso. La ofrenda de la vida es el elemento más socorrido e importante.

El pensamiento religioso de un pueblo, no se aparta de la vida cotidiana, es parte de la costumbre, y de la tradición. Mientras más arraigo tenga, menos necesidad tendrá de explicación. Se le acepta sin discusión. Es ley y tabú; es por lo tanto norma y pertenece al rango sagrado. No es propósito de éste trabajo, hacer un análisis exhaustivo de las diferentes acepciones de los dos términos que hemos mencionado: rito y mito; sin embargo, creemos que fue necesario mencionar el comienzo de su evolución y brevemente, mostrar la ambigüedad con que han sido tratados ambos conceptos.

\footnotetext{
2Jung, Carl G., Los complejos y el inconsciente, alianza editorial, Madrid, segunda edición, 1970, pp. 435-437.
} 
Antes de entrar en materia, conviene establecer una clara distinción del concepto Ceremonial, del latín caeremoniālis tiene tres acepciones de acuerdo con el (DRAE): ha sido considerada ora como "Perteneciente o relativo al uso de las ceremonias; ora como serie o conjunto de formalidades para cualquier acto público o solemne; y libro, cartel o tabla en que están escritas las ceremonias que se deben observar en ciertos actos públicos". En pocas palabras, estas explicaciones no resuelven, con definiciones concretas, el significado del ceremonial, por lo tanto nosotros como ceremonial entendemos el conjunto de normas o fórmulas que rigen con motivo de eventos especiales o ceremoniales. Así explica el significado que tiene la palabra ceremonial un ministro francés en el siglo XIX:

Parece desde luego, en el análisis filosófico, que el ceremonial sea bastante insignificante; pero no se juzga lo mismo, cuando se piensa que la dignidad que en él se observa ejerce una influencia real en el espíritu del pueblo, y que la omisión, por inadvertencia, o repulsa de observar esas graves frioleras, sería considerado como un ultraje. ${ }^{3}$

El ceremonial, luego entonces podría convertirse en un elemento legitimador ${ }^{4}$. En los años de 1836 a 1853 en México, el personaje que más destaca en ese periodo es, el general Antonio López de Santa Anna.

Santa Anna fue presidente de México seis veces, retirándose por cortos periodos y dejando la presidencia en el vicepresidente en varias ocasiones, aquel quien fuera despojado del mando político y militar de Veracruz, quien se levantaría el 2 de diciembre de 1822, para lanzar el Plan de Casa Mata, de 1 de febrero de 1823, que en principio no se dio para desconocer a Iturbide el primer emperador de México, sino para apoyar la libertad del Congreso que había sido sometido por Iturbide, desde ese momento, surgirían México un personaje de tanta valía y significación en la primera mitad del siglo XIX en México, muchas veces criticado por su falta de ideología pero tan importante para nuestro país, Santa Anna utilizaría al ceremonial como ya se mencionó para legitimar su envestidura como presidente de México desde 1842 a 1853.

Revisaremos, en este modesto ensayo dos cuestiones en principio la situación en la cual se encontraba el México en esos años, y en segundo término, revisaremos dos documentos fundamentales para nuestro tema, el ceremonial del funeral del presidente de la República de 1836 y el ceremonial utilizado en las festividades públicas o cualquier tipo de acto en el cual tenga que concurrir el presidente de la República de 1842, ambos casos con una iglesia católica preponderante en México mismo que serían característicos por llevar tintes religiosos en cada ceremonia, como pasaría en toda la primera mitad del siglo XIX en México.

\footnotetext{
${ }^{3}$ Tratado completo de diplomacia o teoría general de las relaciones exteriores, tomo primero; García Torres, Vicente (traductor); Impreso por Juan Ojeda, Méjico, 1838, p. 322.

"Sánchez González, Dolores del Mar "Notas sobre la evolución del protocolo y el ceremonial en España", Estudios institucionales, Revista internacional de investigación en Instituciones, Ceremonial y Protocolo, VOL. II, № 2, Sociedad de estudios institucionales, Madrid, España, 2015, p. 58.
} 


\section{EL CONTEXTO}

Antonio de Padua María Severino López de Santa Anna y Pérez de Lebrón, ocupó el cargo de vicegobernador de Veracruz de diciembre de 1827 a septiembre de 1828, y posteriormente fue elegido gobernador Constitucional del 23 de marzo de 1829 al 2 de enero de 1830.A la postre sería presidente de México en seis ocasiones.

Electos Antonio López de Santa Anna presidente de México por primera vez y Valentín Gómez Farías vicepresidente, Santa Anna pidió licencia para ausentarse por un tiempo y no asumió la presidencia. Para tener una idea más clara de los cambios en la presidencia en este periodo, que explican las inconsistencias del momento entre los años de 1833 a 1847, los señalaremos aquí: Del 1 de abril al 16 de mayo de 1833, gobernó Valentín Gómez Farías; del 16 de mayo al 2 de junio de 1833, fue presidente Santa Anna; del 2 de junio al 17 de junio de 1833, volvió Gómez Farías; Del 17 de junio al 10 de julio de ese mismo año, regresó Santa Anna; del 10 de julio al 28 de octubre, retornó Gómez Farías; del 28 de octubre al 15 de diciembre, repitió Santa Anna; del 15 de diciembre al 24 de abril de 1834, regresó Gómez Farías y del 24 de abril de 1834 al 28 de enero de 1835 volvió nuevamente Santa Anna. ${ }^{5}$ Así, sucesivamente Santa Anna fue presidente de México en muy cortos lapsos de tiempo: del 23 de marzo de 1839 al 10 de julio de 1839; del 10 de octubre de 1841 al 26 de octubre de 1842; 4 de marzo de 1843 al 4 de octubre de 1843; 4 de junio de 1844 al 12 de septiembre de 1844; 21 de marzo de 1847 al 2 de abril de 1847, y del 20 de mayo de 1847 al 16 de septiembre de 1847.

Así pues, con Gómez Farías se dieron las leyes reformadoras: libertad absoluta de opiniones y de prensa; abolición de los privilegios del clero y del ejército; el 17 de agosto se dispone la secularización de las misiones de las Californias; el 31 de agosto las fincas rusticas y urbanas y capitales y bienes pertenecientes a las misiones de Filipinas, quedan a cargo de la Federación; supresión de las instituciones monásticas; prohibición de emplear la coacción en el cobro de diezmos (Ley de 27 de octubre); circular de 31 de octubre, mediante la cual la Secretaría de Justicia ordenaba a los eclesiásticos abstenerse de tocar materias políticas; Ley del 19 de octubre para la supresión de la Real y Pontificia Universidad de México y creación de la Dirección de Instrucción Pública, para evitar la dirección que el clero había tenido en la enseñanza pública, y la desamortización de los bienes del clero; reconocimiento, clasificación y consolidación de la deuda pública; abolición de la pena capital para todos los delitos políticos y aquellos asesinatos que no tuviesen carácter de hecho pensado; garantía de la integridad del territorio por la creación de colonias que tuviesen por base el idioma, usos y costumbres mexicanas; la Ley de 17 de diciembre de 1833 sobre provisión de curatos en la República, donde se señalaba, en su primer artículo, que se deberían de proveer en propiedad, por el presidente de la República en el Distrito y Territorios federales y los gobernadores en los estados, todos los curatos vacantes y que vacaren en la República, por clérigos seculares, observándose lo dispuesto en la Recopilación de Indias de 1680, ejerciendo con ello las facultades que tenían los virreyes; la Ley de 13 de enero de 1834, en

\footnotetext{
${ }^{5}$ Bravo Ugarte, José, Historia de México, V. III, México, Editorial Jus. 1962, p. 498.
} 
que se cedían a los estados de la República los bienes raíces que habían sido propiedad de los jesuitas. ${ }^{6}$

Para sanear la deuda pública, se comenzaron a subastar propiedades del clero; el ejército vio también con alarma las medidas encaminadas al desafuero militar. Algunas órdenes comenzaron a vender sus propiedades susceptibles de ser ocupadas por el gobierno.

El presidente Antonio López de Santa Anna, aprovechando el plan anti reformista proclamado en Cuernavaca el 24 de abril de 1834, regresó a la ciudad de México para hacerse cargo del ejecutivo. Suspendió la aplicación de las leyes reformistas, hasta que un nuevo Congreso determinara su suerte.

En efecto, el nuevo Congreso instalado el 4 de enero de 1835, estaba compuesto por mayoría de diputados y senadores conservadores y federalistas moderados, después de varios meses dieron un golpe de Estado parlamentario al auto decretarse Congreso Constituyente; en octubre se aprobaron las bases para la nueva Constitución.

Las Bases y Leyes Constitucionales de la República Mexicana, conocidas como las Siete Leyes, fueron entregadas por el Congreso desde el 30 de diciembre de 1835 a 1836. Por otra parte, la actividad política en México no cesó mientras estaban vigentes las Siete Leyes, los liberales moderados y los radicales impulsaron revueltas que propiciaron cambios en el gobierno de Anastasio Bustamante. La llegada de Santa Anna, y levantamientos pro liberales auspiciados por Gómez Farías apuraron al Congreso para revisar la Carta del 36. Los acontecimientos que se sucedieron con los acuerdos de 28 de septiembre de 1841, que se firmaron en las llamadas Bases de Tacubaya, estimularon al nuevo Congreso para constituir a la nación, "según conviniera". Las elecciones favorecieron a los liberales moderados. Así se dieron las siguientes:

- Bases de Organización Política de la República Mexicana, que entraron en vigor el 1 de enero de 1844. Este cuerpo jurídico señala Santa Anna ejerció las amplias facultades que le concedían las Bases de Tacubaya sobre todo en materia de exacciones pecuniarias y de impuestos; acudió sin cesar a los bienes de la Iglesia, vendiendo la Hacienda de la Compañía, extinguiendo el Colegio de Todos Santos para apoderarse de sus rentas y haciéndose entregar gruesas sumas en efectivo por algunos obispos y órdenes religiosas. ${ }^{7}$

Pero no sólo a la Iglesia le obligó con impuestos, sino que multiplicó las contribuciones ante la necesidad de pagar las reclamaciones extranjeras, principalmente de Inglaterra y los Estados Unidos. Así que hizo préstamos forzosos que hizo efectivos embargando coches, pianos y muebles; gravó con $20 \%$ de derechos a los artículos que

\footnotetext{
${ }^{6}$ Soberanes Fernández, José Luis, Los bienes eclesiásticos en la historia constitucional de México, México, UNAM, 2000, pp. 41 y 42.

${ }^{7}$ Bravo Ugarte, José op. cit., t. III, p. 191
} 
venían del extranjero, se hizo pagar un impuesto por vehículos y ventanas de las casas, pero no cumplió con informar al Congreso. Pero hay que advertir que fue en este momento en el que se instituyen impuestos que habremos de ver en el siglo XX, como los impuestos predial, sobre tenencia de automóviles, valor agregado etc.

La guerra con Estados Unidos (1846-1848) implicó cambios necesarios ya que faltaba dinero para sufragarla. Desde enero de 1846, el presidente Mariano Paredes pidió una contribución mensual de cincuenta mil pesos a la Arquidiósis de México para sostener la guerra con Estados Unidos,

[...] el Cabildo Metropolitano, sede vacante, aceptó, sin que pudiera cumplir por falta de numerario, por lo cual se cambió dicho compromiso en asumir una hipoteca de dos millones de pesos sobre los bienes de la Iglesia, sin embargo no se logró conseguir prestamistas que acudieran a dar dicho crédito en condiciones razonables [...] finalmente el cabildo dio un donativo de 150,000 pesos. $^{8}$

Un nuevo intento de secularizar los bienes del clero se dio desde el 19 de noviembre de 1846, otra vez con Valentín Gómez Farías como vicepresidente y Santa Anna, quien como presidente pidió permiso al Congreso para ponerse al frente de las tropas que iban a combatir a los norteamericanos, el gobierno decretó que se expidieron letras a cargo del clero hasta por dos millones de pesos para sufragar parte de los gastos de la guerra con los Estados Unidos. Gómez Farías se propuso con la Ley sobre Bienes Eclesiásticos, del 11 de enero de 1847, que el gobierno obtuviese fondos por 15 millones de pesos, para poder continuar la guerra contra la invasión norteamericana, se hipotecaría o vendería en subasta pública los bienes de "manos muertas", en las que se exceptuaba "los bienes de los hospitales, hospicios, casas de beneficencia, colegios, capellanías, edificios y fundaciones y "los objetos indispensables al culto, los bienes de los conventos de religiosos". 9

No se trató de una desamortización de bienes ya que solamente tomaron en cuenta los bienes de la Iglesia y no, como veremos adelante, los bienes de "manos muertas", por ejemplo, los bienes de los ayuntamientos o de las comunidades indígenas.

Sin embargo, la Ley del 11 de enero de 1847 fue abrogada gracias a la sublevación de los batallones de la milicia voluntaria que se habían organizado para combatir a los norteamericanos. Estos batallones integrados por jóvenes acomodados de la ciudad de México, a quienes llamaban "polkos" ya que gustaban de ese baile de moda en la época: la polka, estaban al mando del general Matías de la Peña Barragán, se levantaron contra el gobierno en febrero de 1847, pedían la remoción del vicepresidente Gómez Farías y la derogación de la Ley de Desamortización. Santa Anna regresó a la capital y anuló con la anuencia del Congreso la ley mencionada, haciendo desaparecer la vicepresidencia ya que Gómez Farías se negó a renunciar.

\footnotetext{
${ }^{8}$ Soberanes Fernández, José Luis, Los bienes..., p. 54.

${ }^{9}$ Reyes Heroles, Jesús, El liberalismo mexicano, México, FCE. 1982, t. III, p. 161.
} 
Sin embargo, en plena guerra contra la invasión de Estados Unidos a México, un grupo de liberales, unos moderados y otros "puros", entre los que figuraban José María Lafragua, Octaviano Muñoz Ledo, Juan J. Espinosa de los Monteros, José María Lacunza, Vicente Riva Palacio, Juan B. Ceballos, José María Cardoso, Ignacio Comonfort, Mariano Otero, Valentín Gómez Farías y Benito Juárez, impulsaron en el seno de la Comisión del Congreso Constituyente varias reformas a la Constitución de 1824. Unos querían que se aplicase la Constitución y otros las reformas que impulsaba Otero. Así, el Congreso extraordinario Constituyente sancionó el 18 de mayo de 1847 el Acta Constitutiva de Reformas. En estas reformas se establecen principios como el de

[...] asegurar los derechos del hombre que la Constitución reconoce, [y que] una ley fijará las garantías de libertad, seguridad, propiedad e igualdad de que gozan todos los habitantes de la República y establecerá los medios de hacerlas efectivas. (Artículo 5ㅇ)

También se derogó el cargo de vicepresidente (artículo 15²).

Tiempo después, para 1853 a 1855 el país vivía en un régimen aconstitucional en los que gobernó nuevamente Antonio López de Santa Anna, en su onceavo y último periodo como presidente de la República, en efecto, secundado por varios gobernadores entre los que se encontraba entre otros Juan Álvarez de Guerrero y José María Ortega de Jalisco, Santa Anna, de regreso de su exilio, apoyado en el Congreso que le invistió de los poderes necesarios para que gobernara sin Constitución durante un año y se prorrogó el poder ilimitado que tenía por el tiempo que juzgase necesario; se le concedió facultad de escoger sucesor y se decretó que al cargo de presidentes estuviese anexo el título de "Alteza Serenísima", el 16 de diciembre de 1853. Aunque las propuestas de los aduladores habían sido que tomara el título de "Generalísimo Almirante", y en otras que "Capitán General" o "Príncipe" o "Emperador", según lo señala Riva Palacio, Vicente, en México a través de los siglos. ${ }^{10}$ Mientras que Alamán elaboró las Bases para la administración de la República hasta la promulgación de la Constitución, promulgadas el 23 de abril de 1853.

No es por demás añadir que las relaciones de Santa Anna con la Iglesia en esos años "fueron respetuosas y benévolas; se celebraron con extraordinario esplendor, asistiendo el presidente a las de Catedral (26 marzo 1855), [que fueron] las festividades de la Definición Dogmática de la Inmaculada Concepción". ${ }^{11}$

Por otra parte, el gobierno de Santa Anna, debía seguir el proyecto conservador impulsado por Lucas Alamán entonces ministro de Relaciones, quien tenía el propósito de establecer la monarquía en México. Este era un antiguo proyecto que se manifestó con José María Gutiérrez de Estrada, con la carta que envió el 25 de agosto de 1840 al presidente Anastasio Bustamante, donde señalaba que entre el federalismo y el centralismo como formas de gobierno "son dos altares, uno frente al otro, y cuyo culto sólo conduce a la

\footnotetext{
${ }^{10}$ Riva Palacio, Vicente, México a través de los siglos, México, Editorial Cumbre, S. A. Cuarta y decimoséptima edición, t. IV, p. 823

${ }^{11}$ Bravo Ugarte, José ob. cit., t.III, p. 211.
} 
disensión y a la guerra", sugiere que México no cuenta con hombres preparados que sean capaces de llevarlo a la federación porque los mexicanos vienen de una formación distinta a la de los norteamericanos, porque el fracaso del sistema federal se debe a la subsistencia de clases y costumbres coloniales, por lo que sólo la monarquía podrá salvarlos de sus inconsistencias políticas.

Y Lucas Alamán inspiró una campaña periodística para inclinar a la opinión pública en pro del régimen monárquico. ${ }^{12} \mathrm{~A}$ la muerte de Alamán, el 2 de junio de 1853, llevó adelante el proyecto su sucesor “Manuel Díaz de Bonilla que había escrito al Sr. Gutiérrez de Estrada y a José María Hidalgo, dándoles instrucciones para que solicitaran con todo empeño la intervención de España, Francia e Inglaterra, para traer a México un príncipe español."13

Ante la actitud dictatorial de Santa Anna se inició en el sur del país un movimiento armado donde se pronunciaron en contra del presidente, el 1 de marzo de 1854, con el Plan de Ayutla, firmado por Florencio Villarreal, y que fue secundado y reformado en Acapulco por Juan Álvarez e Ignacio Comonfort; en Michoacán lo siguió Epitacio Huerta; en Oaxaca lo respaldó Porfirio Díaz; en Veracruz lo apoyaron Ignacio de la Llave y otros. Santa Anna se vio obligado a renunciar a la presidencia y el 18 de agosto se embarcó para Turbaco, Nueva Granada (Colombia).

La guerra contra la dictadura de Santa Anna fue una de las guerras internas más largas para derrocar a un gobierno, de 1 de marzo de 1854 a 9 de agosto de 1855 . Arduo y complicado fue convencer a los conservadores y liberales moderados para que asumiera el gobierno Juan N. Álvarez, quien hizo la convocatoria para el Congreso Constituyente el 16 de octubre de 1855.

En efecto, con la victoria del Plan de Ayutla, el 4 de abril de 1855, llegaban al gobierno los liberales radicales o "puros", con ideas propias e influenciadas por el liberalismo europeo y norteamericano. Ellos tenían un proyecto claro de nación que implicaba la formación de un Estado republicano, federal, democrático y laico. Seguían los principios liberales que incluían la libre expresión de las ideas, la igualdad de secularizar a la sociedad para limitar la influencia del clero en la política y en la economía nacional, y pretendían acabar con la bancarrota del país usando los bienes inútiles en "manos muertas". Querían, además, fortalecer al Estado nacional al romper con la interacción entre la Iglesia y el Estado, por lo que renunciaban al Patronato eclesiástico que había imperado en el México independiente y que le facilitaba al gobierno el proponer las dignidades eclesiásticas. Proscribían, también, la coacción civil para el cumplimiento de los votos religiosos y el pago de diezmos y los derechos y obvenciones por servicios religiosos. Para ellos era intrínseco al pensamiento liberal puro y contrario a la intolerancia religiosa, que había imperado en México desde la época colonial, la pretensión de imponer el principio de libertad de cultos.

\footnotetext{
${ }^{12}$ O'Gorman, Edmundo, La supervivencia política novo-hispana. México, Fundación cultural CONDUMEX, S. A. 1969. pp. 29 y ss.

${ }^{13}$ Bravo Ugarte, José. op. cit., t. III, p. 211.
} 
Desterrado Santa Anna, vivió en Nueva York y en 1866 fue declarado traidor a la Patria. En 1867, arribó a la ciudad y puerto de Veracruz sin que se le permitiera desembarcar y finalmente fue hecho prisionero por el jefe militar de Yucatán quién ordenó el asalto del buque Virginia en el que viajaba Santa Anna. Fue conducido a la ciudad de Campeche y puesto a disposición del gobierno juarista, fue encarcelado en San Juan de Ulúa y juzgado en consejo de Guerra; se le impuso la pena del destierro por 8 años en Nassau, en las Bahamas. A la muerte de Benito Juárez en 1872, el Presidente Sebastián Lerdo de Tejada, paisano y amigo del caudillo, le permitió volver al país en 1874. Para ese entonces no se le reconoció su grado militar y se le negó la devolución de sus bienes y sueldos confiscados. Murió en la ciudad de México el 21 de junio de 1876.

\section{DOS ACTOS CEREMONIALES EN LA PRIMERA MITAD DEL SIGLO XIX EN MÉXICO}

Durante la vigencia del centralismo en México se dictaron dos Leyes relativas al ceremonial: una el 29 de febrero de 1836 con el nombre Ley sobre el funeral que debe observarse en la República mexicana por el fallecimiento del presidente, bajo la presidencia de Miguel Francisco Barragán Ortiz presidente interino mientras que el presidente Santa Anna descansaba en su hacienda de Manga de Clavo Veracruz y otra el de 9 de junio de 1842, durante la presidencia ahora si de Antonio López de Santa Anna, con el nombre de Ceremonial que deberé observarse en las asistencias del presidente de la República a las festividades o actos públicos de cualquier clase.

\section{Ley sobre el funeral que debe observarse en la República mexicana por el fallecimiento del presidente de 29 de febrero de 1836.}

La ley sobre el funeral, está conformada por 12 artículos y 10 disposiciones reglamentarias, en ella se establece que luego que los facultativos de cabecera anuncien al secretario de despacho de Relaciones haber fallecido el presidente de la República, dispondrá aquel que dos escribanos públicos den fe y testimonio y poniéndolo en conocimiento del poder ejecutivo, hagan las comunicaciones correspondientes al congreso y a la Suprema Corte de Justicia. Se comunicará a todas las autoridades civiles, eclesiásticas y militares de toda la República.

Se anunciaría con cuatro cañonazos consecutivos por la batería de palacio, una descarga por toda la del cuartel de esta arma y cien campanadas en todas las iglesias. Asimismo, el cadáver se expondrá por tres días al público, en el cual se celebrarán misas por el cabildo, parroquias y comunidades. De igual forma, el cadáver, desde que sale de palacio la procesión fúnebre, se disparará un cañonazo cada cuarto de hora, también, se vestirá de luto público por un mes (las primeras autoridades civiles y judiciales, y los jefes de oficina de los Departamentos, Distrito y Territorios...), las exequias fúnebres se harán en la Santa Catedral y en la misma se sepultará el cadáver en la capilla de los Santos Reyes.

Por último, el presidente en ejercicio recibirá el pésame, arreglando previamente el ceremonial de este acto. Los gastos del funeral serán dispuestos por la hacienda pública. Dentro de las disposiciones reglamentarias destacan las siguientes: el primero de los tres 
días en que debe estar expuesto el cadáver, se celebrarán mismas rezadas particulares en el salón donde se halle el cuerpo, el segundo día se cantarán misas por el venerable cabildo y las parroquias, y el tercer día por las comunidades religiosas.

El tercer día de la exposición del cadáver, a las ocho de la mañana se reunirán en Palacio Nacional todas las corporaciones y autoridades, para ordenar la procesión fúnebre que se dirigirá por las calles de Seminario, Escalerillas, Tacuba, Santa Clara, Vergara, San Francisco, plateros y Parian a entrar por la puerta principal de la Catedral. Procesión: una escuadra de gastadores de caballería, seis cañones de campaña, con su destacamento de artillería; tres caballos enlutados; el sargento mayor de plaza, sus ayudantes, dos coroneles y dos tenientes coroneles, todos a caballo, con espada en mano; las compañías de granaderos de los cuerpos; treinta pobres del hospicio, con hachas encendidas, presididos por el director y capellán del establecimiento; toda la comitiva religiosa, seis alumnos del Colegio Militar llevaran la tapa de la caja de ataúd, a esta seguirá el cuerpo entre dos hileras de gastadores de infantería, a cuyo centro marcharan los ayudantes de la persona; será conducido el cadáver por sargentos y llevaran las borlas del ataúd dos generales de división, el director general de rentas, un ministro de la Tesorería general, un miembro del ayuntamiento y uno de la Universidad; después de cadáver marchará el comandante general con todo el Estado Mayor general, y detrás la compañía de guardia del difunto, con bandera arrollada; a continuación irá la comitiva del duelo. Los balcones de la carrera se adornarán con cortinas blancas y lazos negros. Después de sepultado el cadáver recibirán la llave de la caja los dos secretarios del despacho que asistan el entierro, la que se custodiará en el archivo secreto del ministerio de Relaciones.

Decreto del gobierno del 9 de junio de 1842, del ceremonial que deberá observarse en las asistencias del presidente de la República a las festividades o actos públicos de cualquier clase.

Antonio López de Santa Anna, en su sexto periodo como presidente de la República, del 10 de octubre de 1841 al 26 de octubre de 1842, mandó a publicar y circular el debido cumplimiento del decreto del ceremonial que debería observarse en las asistencias del presidente de la República a las festividades o actos públicos de cualquier clase. De conformidad con el artículo 7ำ de las Bases de Tacubaya del 28 Septiembre de 1841 en las que se habla de la envestidura en donde se permitía al ejecutivo provisional, que tendrá las facultades para la organización de todos los ramos de la administración pública.

En dicho decreto se estableció el ceremonial para que en las fiestas nacionales y eclesiásticas, o de cualquier índole, en el que tenga que concurrir el ejecutivo públicamente, conforme a las leyes, se ejecute con el acompañamiento que exige su dignidad.

El ceremonial consta de 7 artículos, en los cuales pone énfasis en los recibimientos de corporaciones o individuo por parte del Jefe de palacio en el Palacio, dicho Jefe estaría encargado de la etiqueta de la reunión hasta preeminencia en algún salón del Palacio y órdenes supremas que tenga sobre el particular (entendiendo lo anterior cualquier instrucción que tenga el jefe para cualquier evento en Palacio). También, el ceremonial 
atiende los traslados del Palacio a la iglesia, en los que será ordenada por el jefe del palacio, quien arreglara el traslado en dos hileras: primeramente los colegios y comunidades religiosas, después las autoridades del departamento, seguida por los cuatro Ministerios, los ministros de Tesorería, jefes de oficina de Hacienda, superintendente de la casa de Moneda, director general de rentas, contadores mayores del tribunal de revisión de cuentas, oficiales mayores. Después, los ministros de la Suprema Corte de Justicia y marcial y demás funcionarios etc.

De igual forma, se señala en el decreto del ceremonial los lugares dentro de la iglesia: el presidente bajo el dosel siguiendo por su izquierda los secretarios del despacho, la Suprema Corte de Justicia y marcial, los oficiales mayores, ministros de la Tesorería general, director general de rentas, superintendente de la casa d moneda y jefes de oficinas generales de hacienda hasta llegar al presbítero; y detrás en segunda fila los oficiales de los cuatro ministerios. En frente de estos asientos, al otro lado de la crujía se colocarán en bancas las autoridades del ayuntamiento. Al costado, del lado derecho del presidente de la República, se colocará el jefe de la plana mayor del ejército, siguiéndole los generales, y detrás los ayudantes del presidente y del jefe de plana mayor etc. Asimismo, el ceremonial establece si la asistencia del presidente es en algún lugar diferente se seguirá el mismo orden de prelación de las personas al sentarse. Por último, dicho decreto menciona las felicitaciones dirigidas al presidente de la República el cual señala solamente que se harán en los días de fiestas nacionales o en otros semejantes se practicaran, después de la del cuerpo diplomático, por las autoridades y corporaciones respectivas.

\section{CONCLUSIONES}

- La marcada ceremonia con la que se celebran las distintas fases en los funerales pone de relieve el sentido y el significado de los rituales funerarios. Comprendiendo así la complejidad del ceremonial de la muerte de un presidente de la República en el que cada parte depende de muchos factores. Por un lado, los que marcan el ritual litúrgico (la presencia del sacerdote, las oraciones...) y por otro del protocolo público administrativo, el orden de las comitivas, la presencia de grandes personajes etc. Mientras que en la defunción de un simple ciudadano la ceremonia estaría marcada por la liturgia y las tradiciones populares.

- Los actos públicos del presidente de la República, deben de estar reglamentados en una ley o un decreto, como pudimos observar en los párrafos anteriores se estableció en el siglo XIX dichas leyes. En donde los actos, que se celebran para conmemorar una fecha o un acontecimiento, ora para legitimar la envestidura del presidente de la República (juramento a la Constitución), ora primeras piedras, o difundir públicamente cambios de status, son actos de una especial solemnidad que estaban establecidos en la primera mitad del siglo XIX en México y reglamentados en ley. Lamentablemente, en la actualidad existe esa falta de reglamentación, sobre todo, en los actos en que concurren los tres poderes (ejecutivo, legislativo y judicial). Ya que en los actos públicos en donde concurre el presidente de la República o los tres 
poderes, carece de formalidades que deberían de ser del mayor interés para el gobierno, pues todo acto público, para que tenga sentido, pretende transmitir, un determinado mensaje a la ciudadanía. El protocolo es necesario en los actos oficiales si queremos darles la dignidad que merecen y que se reconozcan los privilegios a que tienen derecho sus participantes. En la ordenación del protocolo hay que hablar de normas, y el criterio para definirlas no es su carácter de obligatoriedad sino a su finalidad. Esto quiere decir, ordenar el protocolo es crear reglas que deben de presidir la celebración del acto en que intervienen autoridades de distinta clase.

- Lamentamos profundamente, que no exista y que no existirá en un futuro cercano una oficina dedicada al protocolo específicamente de la presidencia de la República mexicana, la cual coordine todo lo relacionado con los actos públicos del gobierno en la actualidad. Seguiremos, observando infinidad de errores en el protocolo de los actos públicos en donde concurra el presidente de la República incluso en los diplomáticos por falta de una ley o decreto.

\section{BIBLIOGRAFÍA}

Bravo Ugarte, José, Historia de México, V. III, México, Editorial Jus. 1962.

Jung, Carl G., Los complejos y el inconsciente, alianza editorial, Madrid, segunda edición, 1970.

O'Gorman, Edmundo, La supervivencia política novo-hispana. México, Fundación cultural CONDUMEX, S. A. 1969.

Sánchez González, Dolores del Mar "Notas sobre la evolución del protocolo y el ceremonial en España", Estudios institucionales, Revista internacional de investigación en Instituciones, Ceremonial y Protocolo, VOL. II, № 2, Sociedad de estudios institucionales, Madrid, España, 2015.

Reyes Heroles, Jesús, El liberalismo mexicano, México, FCE. 1982, tres tomos.

Riva Palacio, Vicente, México a través de los siglos, México, Editorial Cumbre, S. A. Cuarta y decimoséptima edición, t. IV.

Soberanes Fernández, José Luis, Los bienes eclesiásticos en la historia constitucional de México, México, UNAM, 2000.

Tratado completo de diplomacia o teoría general de las relaciones exteriores, tomo primero; García Torres, Vicente (traductor); Impreso por Juan Ojeda, Méjico, 1838.

Legislación mexicana o colección completa de las disposiciones legislativas expedidas desde la independencia de la República. Ordenada por los licenciados Manuel Dublán y José María Lozano. Número 22344 y 2818, decreto de 9 de junio de 1842, y 29 de febrero de 1836, imprenta del comercio, México 1876. 
(C) (1) This work is licensed under a Creative Commons Attribution 4.0 Unported License 